\title{
Improved metabolic disorders of insulin receptor-deficient mice by transgenic overexpression of glucokinase in the liver
}

\author{
M. Jackerott, A. Baudry, D. Bucchini, J. Jami, R. L. Joshi \\ Department of Genetics, Development and Molecular Pathology, Cochin Institute, INSERM, CNRS, \\ University of René Decartes, Paris, France
}

\begin{abstract}
Aims/hypothesis. Insulin receptor null mutant mice develop severe diabetes, ketoacidosis and liver steatosis and die within 1 week after birth. Since the liver plays an essential role in the control of glucose homeostasis, we examined in this work whether the metabolic disorders of insulin receptor-deficient mice could be improved upon restoration of hepatic glucose metabolism by transgenic constitutive overexpression of glucokinase selectively in the liver.

Methods. We first generated transgenic mice overexpressing rat glucokinase cDNA under control of the liver-specific phenylalanine hydroxylase gene promoter. These transgenic mice were crossed with heterozygous insulin-receptor-null mutants to produce homozygous insulin-receptor-null mice overexpressing glucokinase in the liver.

Results. The transgenic mice overexpressing glucokinase in the liver showed improved glucose tolerance and were mildly hypoglycaemic and hyperlipidaemic
\end{abstract}

under starved conditions. The introduction of the glucokinase transgene in insulin receptor null mice did not prevent the development of glycosuria. However, ketoacidosis was delayed by more than 1 week and survival was prolonged to 10 to 16 days in $16 \%$ of the pups. In these longer surviving pups, serum glucose and triglyceride concentrations were lowered, hepatic glycogen stores were reconstituted and liver steatosis was absent as compared with the pups which had developed strong ketoacidosis and died earlier.

Conclusions/interpretation. These results show that overexpression of hepatic glucokinase can compensate, in part, for the metabolic disorders developed by insulin receptor-deficient mice. This shows the importance of improving hepatic function in diabetes and must revive interest in enhancement of glucokinase activity as a therapeutic strategy for the treatment of diabetes. [Diabetologia (2002) 45:1292-1297]

Keywords Insulin receptor, glucokinase, liver, diabetes, knockout mice, transgenic mice.
Insulin plays a vital role in glucose homeostasis by regulating carbohydrate, lipid and protein metabolism. Insulin action is mediated by the insulin receptor (IR) which belongs to the family of membrane receptors

Received: 4 February 2002 / Revised: 9 April 2002

Published online: 31 July 2002

(C) Springer-Verlag 2002

Corresponding author: Dr. R. L. Joshi, GDPM, Institut Cochin, 24, rue du Faubourg Saint-Jacques, 75014 Paris, France, E-mail: joshi@cochin.inserm.fr

Abbreviations: DKA, Diabetic ketoacidosis; GK, glucokinase; IR, insulin receptor; LIRKO, liver-specific insulin receptor knockout; PAH, phenylalanine hydroxylase; TBP, TATA binding protein; wt, wild-type with tyrosine kinase activity [1]. Although IR is widely distributed in the body, the three major target tissues in which insulin exerts important metabolic effects are muscle, liver and fat tissue.

The crucial role of IR in insulin action was confirmed by targeted disruption of the $I R$ gene $[2,3]$. IRdeficient mice developed severe metabolic disorders soon after suckling, leading to diabetes mellitus, diabetic ketoacidosis (DKA) and liver steatosis, and died within 1 week after birth. Recently, the IR gene was also disrupted in major insulin target tissues such as muscle or liver using the Cre-loxP strategy $[4,5]$. These studies concluded that insulin action in the liver plays an essential role in the control of glucose ho- 
meostasis. We therefore hypothesized whether the metabolic disorders resulting from global IR deficiency could be improved upon restoration of glucose metabolism selectively in the liver of $\mathrm{IR}^{-1-}$ mice.

It is well documented that glucokinase $(\mathrm{GK})$, which catalyses the initial conversion of glucose to glucose6-phosphate, is a key factor in hepatic control of glucose homeostasis [6, 7]. Studies focused on GK gained particular attention since the discovery that MODY-2 is associated with mutations in the $G K$ gene resulting in reduced GK activity in both liver and beta cells $[8,9]$. Lower hepatic GK activity was also reported in a group of patients with Type II (non-insulin-dependent) diabetic mellitus patients [10]. It was thus proposed that increasing $G K$ gene expression or enzyme activity in the liver in a constitutive manner could be a means for normalizing hyperglycaemia resulting from insulin deficiency or defective insulin signalling. To evaluate the effect of GK overexpression on hepatic function and fuel homeostasis under various physiological conditions, several groups have generated rodent models overexpressing GK in the liver either by transgenesis or adenovirus-mediated transfer $[11,12,13,14]$. These transgenic mice showed lower fasting blood glucose concentrations, improved glucose tolerance and increased glycogen synthesis in the liver as compared to wild-type (wt) mice. More importantly, it was shown that GK overexpression in the liver prevents the development of hyperglycaemia or diabetes induced by streptozotocin or a high-fat diet $[15,16,17]$.

In this study, we decided to test whether transgenic constitutive overexpression of GK in the liver of $\mathrm{IR}^{-1-}$ mice can restore hepatic glucose metabolism and improve the metabolic disorders developed by these mutants. In order to achieve this, we generated a new line of transgenic mice overexpressing rat $G K$ cDNA under control of the liver-specific human phenylalanine hydroxylase $(P A H)$ gene promoter [18]. This promoter was chosen to direct expression of the $G K$ transgene in the liver of $\mathrm{IR}^{-/}$pups since it was shown to be expressed from late embryonic stages and to remain active under diabetic conditions $[18,19]$.

\section{Materials and methods}

Construction of the GK transgene. A $9 \mathrm{~kb}$ EcoRI-SmaI fragment from pCPH15E 9 (obtained from Dr. S. Woo, New York, N.Y., USA) containing the 5'-flanking region, enhancer, promoter and $1^{\text {st }}$ intron of the human phenylalanine hydroxylase $(\mathrm{PAH})$ gene was cloned into $\mathrm{pSK}^{+}$at the ClaI site using ClaI linkers (pSK-PAH). Subsequently, a $2.3 \mathrm{~kb} E c o R I$ fragment from pB-GK2 (obtained from Dr. P. Iynedjian, Geneva, Switzerland) containing the rat cDNA encoding liver GK isoform was cloned into pSK-PAH at the HindIII site using HindIII linkers (pSK-PAH/GK). In parallel, a $1.6 \mathrm{~kb}$ BglII-EcoRI fragment from pIF46 (obtained from Dr. I. Barlat, Paris, France) containing the SV 40 poly A signal was inserted at the EcoRI site in $\mathrm{pSK}^{+}$using EcoRI linkers (pSK-PolyA). Finally, the
SmaI-SalI fragment from pSK-PAH/GK containing the $P A H$ promoter/GK cDNA was inserted into pSK-PolyA using EcoRV-SalI sites to obtain pSK-PAH/GK/PolyA plasmid.

Generation of transgenic mice. The $13 \mathrm{~kb}$ SmaI-SalI DNA fragment from $\mathrm{pSK}-\mathrm{PAH} / \mathrm{GK} / \mathrm{PolyA}$ containing the transgene cassette was microinjected into the pronucleus of zygotes followed by retransplantation into pseudogestant female mice using standard procedures [20]. Transgenic mice among the offspring were identified by PCR, carried out on tail DNA using Taq DNA polymerase (Promega, Madison, Wis., USA) and the following primers $\left(5^{\prime}\right.$-GTG CCT GTG AAA GCG TGT CC-3'/5'-GGT GAT TTC GCA GTT GGG TG-3'), which produced a PCR product of $206 \mathrm{bp}$ deriving from the $G K$ transgene. Founder animals were bred with [C57BL6xCBA]F1 mice to establish $G K$ transgenic lines and a line with a high expression of the transgene (L-GK) was identified.

Production of mice with targeted disruption of the $I R$ gene has been described [3]. The $\mathrm{IR}^{+/-}$mice were crossed with the $\mathrm{L}-\mathrm{GK}$ transgenic line to generate $\mathrm{IR}^{+/-}$mice carrying the $G K$ transgene. These were subsequently intercrossed to obtain $\mathrm{IR}^{-1-}$ mice with $G K$ transgene expression.

All mice were maintained in a normal light to dark cycle of $12 \mathrm{~h}$ and fed on a standard diet ad libitum. Homozygous transgenic male mice were analysed at the age of 2 to 3 months. Age-matched [C57BL6xCBA]F1 male mice were used as controls. These studies were carried out according to the French animal ethical regulations.

RT-PCR analysis. Total RNA was extracted using RNAzol (Campro Scientific, Veenendaal, The Netherlands) from tissue frozen in liquid $\mathrm{N}_{2}$. The RNA samples were treated with DNase (Promega) and then subjected to RT-PCR (Access RT-PCR, Promega) using primers common for the rat or mouse $G K$ coding sequence $\left(5^{\prime}\right.$-CAC CCA ACT GCG AAA TCA CC-3'/5'-CAT TTG TGG GGT GTG GAG TC-3'). These primers anneal to a region of the $G K$ gene showing no homology to other hexokinase genes. As an internal control, TATA binding protein $(T B P)$ mRNA was coamplified using the following primers (5'-AAG AGA GCC ACG GAC AAC TG-3'/5'-TAC TGA ACT GCT GGT GGG TC-3'). The following reaction cycles were used: $48^{\circ} \mathrm{C}$ for $45 \mathrm{~min}, 94^{\circ} \mathrm{C}$ for $2 \mathrm{~min}$, followed by 24 cycles of $94^{\circ} \mathrm{C}$ for $30 \mathrm{~s}, 60^{\circ} \mathrm{C}$ for $1 \mathrm{~min}$ and $68^{\circ} \mathrm{C}$ for $2 \mathrm{~min}$, and finally $68^{\circ} \mathrm{C}$ for $7 \mathrm{~min}$ which allowed exponential co-amplification at equal rates of GK and $T B P$ mRNAs. The PCR products were digested with MspI, which digests the PCR product amplified from the rat $G K$ transgene but not that derived from the endogenous murine $G K$ gene. The DNAs were run on $3 \%$ agarose gels, transferred onto Hybond membranes, hybridised at $42^{\circ} \mathrm{C}$ using [32P]-labelled oligonucleotides probes $\left(5^{\prime}\right.$-[32P]-GGG CCA GTG AAA TCC AGG CA-3' for $G K$ and 5'-[32P]-GAG TTG TGC AGA AGT TGG GC-3' for TBP) and exposed to X-ray films. The lengths of the PCR products detected were $162 \mathrm{bp}$ (mouse $G K$ ), $66 \mathrm{bp}$ (rat $G K$ ) and 233 bp $(T B P)$. Quantification of mouse or rat $G K$ RT-PCR products was carried out using a Phosphorimager equipped with ImageQuant software (Molecular Dynamics, Sunnyvale, Calif., USA) and expressed in relation to TBP control.

GK activity assay. Fresh liver samples were homogenized in 10 volumes of ice-cold buffer containing $50 \mathrm{mmol} / \mathrm{l}$ Tris- $\mathrm{HCl}$ pH 7.4, $300 \mathrm{mmol} / \mathrm{l}$ sucrose, $100 \mathrm{mmol} / \mathrm{l} \mathrm{KCl}, 1 \mathrm{mmol} / \mathrm{l}$ EDTA and $0.7 \mu \mathrm{l} / \mathrm{ml} \quad \beta$-mercaptoethanol and centrifuged at 12 $000 \mathrm{rpm}$ for $1 \mathrm{~h}$. The GK activity was measured in supernatants as described [21]. The assays were carried out in a solution containing $50 \mathrm{mmol} / \mathrm{l}$ HEPES $\mathrm{pH} 7.4,100 \mathrm{mmol} / \mathrm{l} \mathrm{KCl}$, 
$7.5 \mathrm{mmol} / \mathrm{l} \mathrm{MgCl}_{2}, 2.5 \mathrm{mmol} / 1 \mathrm{DTT}, 0.5 \mathrm{mmol} / \mathrm{l} \mathrm{NAD}+1 \%$ BSA, $0.5 \mathrm{mmol} / \mathrm{l}$ or $100 \mathrm{mmol} / \mathrm{l}$ glucose, and $3.4 \mathrm{U} / \mathrm{ml} \mathrm{glu}-$ cose-6-phosphate dehydrogenase (Sigma, St. Louis, Mo., USA). The reactions were initiated by adding $5 \mathrm{mmol} / \mathrm{l}$ ATP and the rate of increase in absorbance at $340 \mathrm{~nm}$ was measured. The GK activity was calculated as the difference between the kinase activity measured at $100 \mathrm{mmol} / \mathrm{l}$ (total kinase activity) and $0.5 \mathrm{mmol} / \mathrm{l}$ glucose (hexokinase activity). Protein concentrations in liver homogenates were measured using the Bradford method (Bio-Rad protein Assay, Bio-Rad Laboratories, Hercules, Calif., USA) using BSA as standard.

OGTT. Glucose tolerance tests were carried out on 2-monthold transgenic or control mice after overnight fasting $(20 \mathrm{~h})$ by oral administration of glucose $(2 \mathrm{~g} / \mathrm{kg}$ body weight $)$ at time zero. Blood samples were collected from the orbital sinus at the indicated times and serum glucose concentrations were measured using glucose assay kits (Sigma Diagnostics).

Metabolite and hormone assays. Blood samples were obtained from the orbital sinus of adult mice or from newborn mice after decapitation. Glucose, triglyceride and lactate concentrations in the serum were measured by enzymatic assays using colorimetric kits (Sigma). Serum insulin concentrations were quantified by RIA kits (ICN Pharmaceutical, Costa Mesa, Calif., USA). Urinary glucose and ketone body contents were analysed using Keto-Diastix strips (Bayer Corporation, Tarrytown, N.Y., USA). Liver glycogen contents were measured in perchloric extracts adjusted to $\mathrm{pH} 5$ with $\mathrm{K}_{2} \mathrm{CO}_{3}$ using the $\alpha$-amyloglucosidase method [22].

Histology. Liver samples were fixed in $4 \%$ paraformaldehyde, dehydrated and embedded in paraffin. De-waxed tissue sections $(5 \mu \mathrm{m})$ were stained with hematoxylin and eosin.

Statistical analysis. Data are expressed as means \pm SEM. Analysis of statistical differences was carried out using the independent two-tailed Student's t test. Differences were considered statistically significant with a $p$ value of less than 0.05 .

\section{Results}

Generation of transgenic mice overexpressing GK in the liver. We first created transgenic mice overexpressing GK in the liver. For this purpose, rat GK cDNA was placed under control of the human PAH gene promoter. The $P A H$ promoter- $G K$ cDNA-Poly A construct (Fig. 1A) was injected into the pronucleus of zygotes and eight founder transgenic mice were obtained. Transgenic offspring resulting from the breeding of the founder mice with non-transgenic mice were analysed for expression of the transgene by RT-PCR using total RNA from the liver. From this analysis, one transgenic line designated L-GK showed approximately eightfold higher total GK mRNA content as compared to those found in non-transgenic mice after an overnight fast (Fig. 1B). Under starved conditions, endogenous $G K$ gene expression was decreased compared to non-fasted animals. However, GK transcripts derived from the endogenous gene remained clearly detectable in fasted animals by the RT-PCR assay used in the analysis. As a result of increased amount of endogenous $G K$
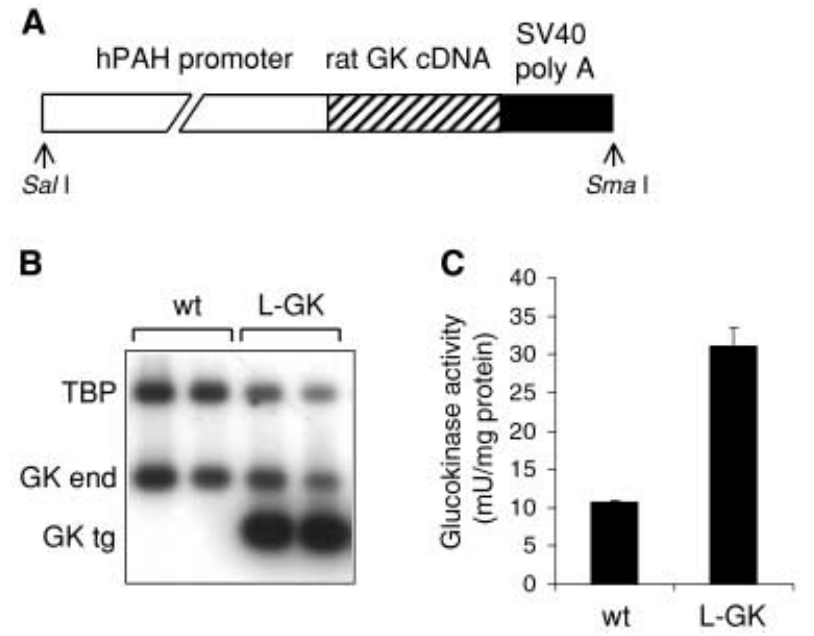

Fig. 1 A-C. Obtention of L-GK transgenic mice overexpressing GK in the liver. A Schematic representation of the chimeric human PAH promoter/rat GK cDNA transgene construct. A $13 \mathrm{~kb}$ SalI-SmaI fragment containing the entire transgene cassette was used to generate transgenic mice. B Transgene expression in the liver of L-GK mice. GK transcripts from the endogenous gene ( $\mathrm{GK}$ end) or the transgene ( $\mathrm{GK} \mathrm{tg}$ ) were analysed by RT-PCR using total RNA prepared from the liver of adult starved wt and L-GK mice. TBP mRNA was coamplified as a control. The sizes of the RT-PCR products for GK end, GK tg and TBP correspond to $162 \mathrm{bp}, 66 \mathrm{bp}$ and 233 bp, respectively. C GK activity in the liver of L-GK mice. GK activity was analysed in liver extracts from adult starved wt and L-GK mice. The results shown are means \pm SEM of $6 \mathrm{wt}$ and $10 \mathrm{~L}-\mathrm{GK}$ animals

mRNA, total GK transcripts in non-fasted transgenic mice were increased only about fourfold as compared to non-transgenic control mice. The increase in $G K$ gene expression resulted in about threefold higher levels of total GK activity in liver extracts from transgenic mice as compared to control mice in the fasting state (Fig. 1C). Expression of the transgene was also analysed at the neonatal stage. In 2-day-old mice, the GK activity in liver extracts from transgenic pups $(8.35 \pm 1.64 \mathrm{mU} / \mathrm{mg}$ protein) was increased approximately fourfold as compared to non-transgenic littermates $(2.12 \pm 0.91 \mathrm{mU} / \mathrm{mg}$ protein). To examine tissuespecificity of transgene expression, total RNA extracted from various organs of non-fasted L-GK mice was analysed by RT-PCR (Fig. 2). This analysis showed weak expression of the transgene in the kidney, while no transgenic expression was detected in other insulinresponsive tissues such as muscle or adipose tissue.

The L-GK mice were further analysed to examine the effects of GK overexpression on glucose disposal. In OGTT, L-GK mice showed faster glucose clearance from the blood when compared to control animals (Fig. 3). Following overnight starvation, the L-GK mice were mildly hypoglycaemic while serum insulin concentrations were unchanged as compared to control mice. Upon overnight starvation, L-GK mice showed increased concentrations of serum triglyce- 


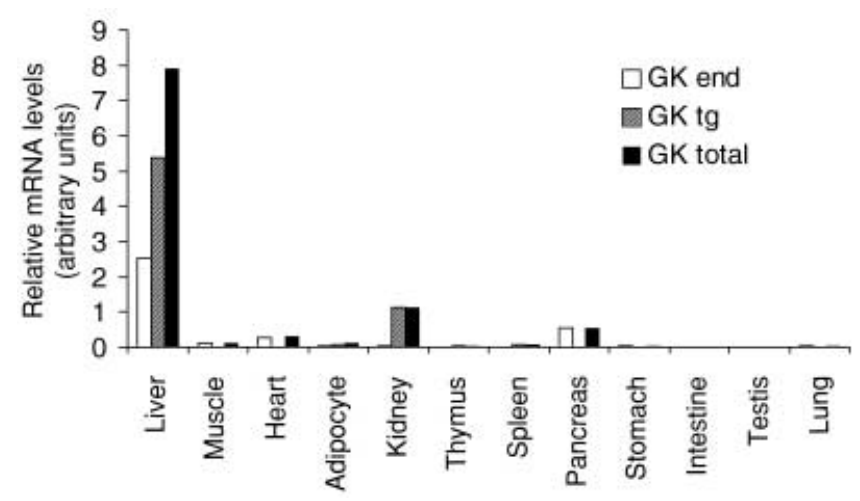

Fig. 2. Analysis of tissue-specificity of transgene expression in L-GK mice. GK transcripts were analysed by RT-PCR using total RNA prepared from different organs of normally fed adult L-GK mice. The quantitative data are shown as the ratio of the intensities of bands corresponding to GK transcripts from the endogenous gene (GK end) or the transgene ( $\mathrm{GK} \mathrm{tg}$ ) in relation to band intensity for TBP that was co-amplified as a control

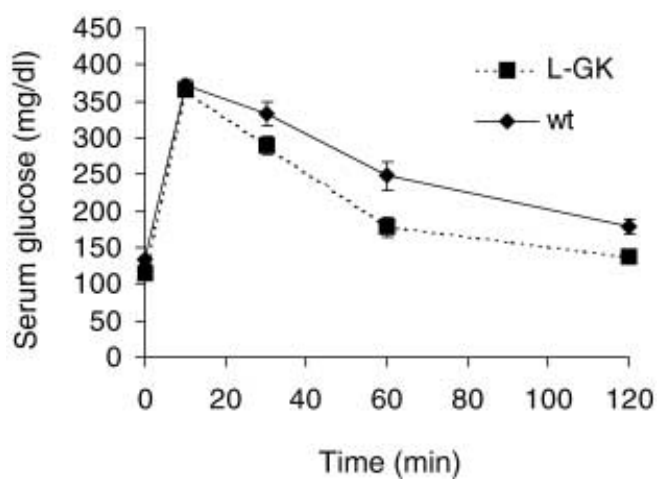

Fig. 3. OGTT. Both wt and L-GK mice were starved for $20 \mathrm{~h}$ and given glucose orally ( $2 \mathrm{~g} / \mathrm{kg}$ body weight). The glucose concentrations were measured in blood samples collected from orbital sinus before and after glucose load at the times indicated. Data shown are means \pm SEM of 16 wt and 17 L-GK mice rides $(1.15 \mathrm{~g} / \mathrm{l} \pm 0.13 \mathrm{~g} / \mathrm{l}$ in $\mathrm{L}-\mathrm{GK}$ mice $(n=8)$ vs $0.81 \mathrm{~g} / \mathrm{l} \pm 0.08 \mathrm{~g} / \mathrm{l}$ in wt mice $(n=8), p<0.05)$ and slightly higher circulating lactate concentrations as compared to control mice $[0.312 \mathrm{~g} / \mathrm{l} \pm 0.026 \mathrm{~g} / 1$ in $\mathrm{L}-\mathrm{GK}$ mice $(n=8)$ vs $0.236 \mathrm{~g} / 1 \pm 0.036 \mathrm{~g} / 1$ in wt mice $(n=8)]$.

Improved metabolic disorders of $I R^{-/}$mice overexpressing liver GK. To evaluate whether GK overexpression in the liver of IR-deficient mice could improve the metabolic disorders developed by these mutants, L-GK mice were crossed with heterozygous IR null mutants and $\mathrm{IR}^{+/}$mice carrying the transgene were recovered. These $\mathrm{IR}^{+/} \mathrm{L}-\mathrm{GK}$ mice were subsequently intercrossed and 99 diabetic pups obtained in the progeny were analysed.

The results of genotyping indicated that 22 pups were $\mathrm{IR}^{--}$and 77 pups were $\mathrm{IR}^{-/} \mathrm{L}-\mathrm{GK}$. As expected, all $\mathrm{IR}^{-/-}$mutants rapidly developed severe DKA and liver steatosis, and they all died within 7 days after birth. The majority of $\mathrm{IR}^{-/} \mathrm{L}-\mathrm{GK}$ pups developed DKA and liver steatosis at $\mathrm{P} 3-5$ as $\mathrm{IR}^{-1-}$ mutants. These pups also died within 7 days after birth. However, $16 \%$ of $\mathrm{IR}^{-/}$L-GK mice (12 pups) showed no DKA for more than 1 week and survived for a longer period (10-16 days). These pups however remained smaller and weighed about 35\% less than wt littermates. We verified that the transgene was expressed and GK activity was increased in the liver of these longer-surviving pups.

The metabolic parameters in the early-dying and longer-surviving $\mathrm{IR}^{-1} \mathrm{~L}-\mathrm{GK}$ pups as well as in the agematched non-diabetic L-GK control mice were analysed. As shown in Figure 4, IR $\mathrm{IR}^{-/} \mathrm{L}-\mathrm{GK}$ pups surviving more than 10 days without DKA showed reduced concentrations of serum glucose and triglycerides compared to $\mathrm{IR}^{-/} \mathrm{L}-\mathrm{GK}$ pups with early development of DKA. The serum glucose and triglyceride concentrations in $\mathrm{IR}^{-1}$ L-GK pups with early DKA were similar

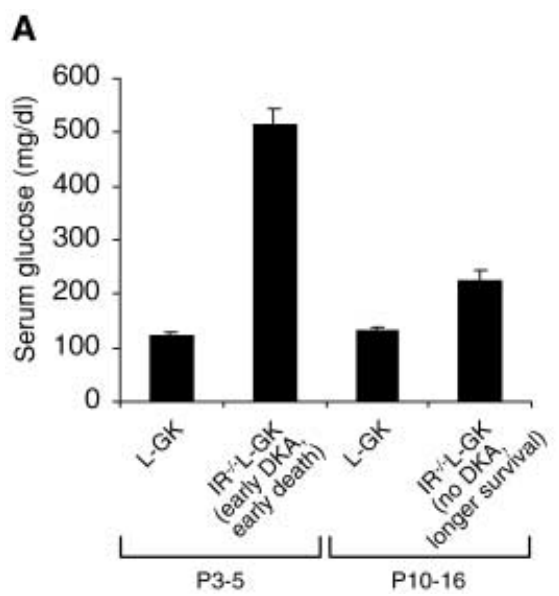

Fig. 4 A-C. Improved metabolic parameters in longer surviving $\mathrm{IR}^{-/}$L-GK pups. Serum glucose (A), serum triglycerides (B) and hepatic glycogen content (C) were measured for longer-surviving $\mathrm{IR}^{-l} \mathrm{~L}-\mathrm{GK}$ pups without $\mathrm{DKA}$ or $\mathrm{IR}^{-/-} \mathrm{L}-\mathrm{GK}$
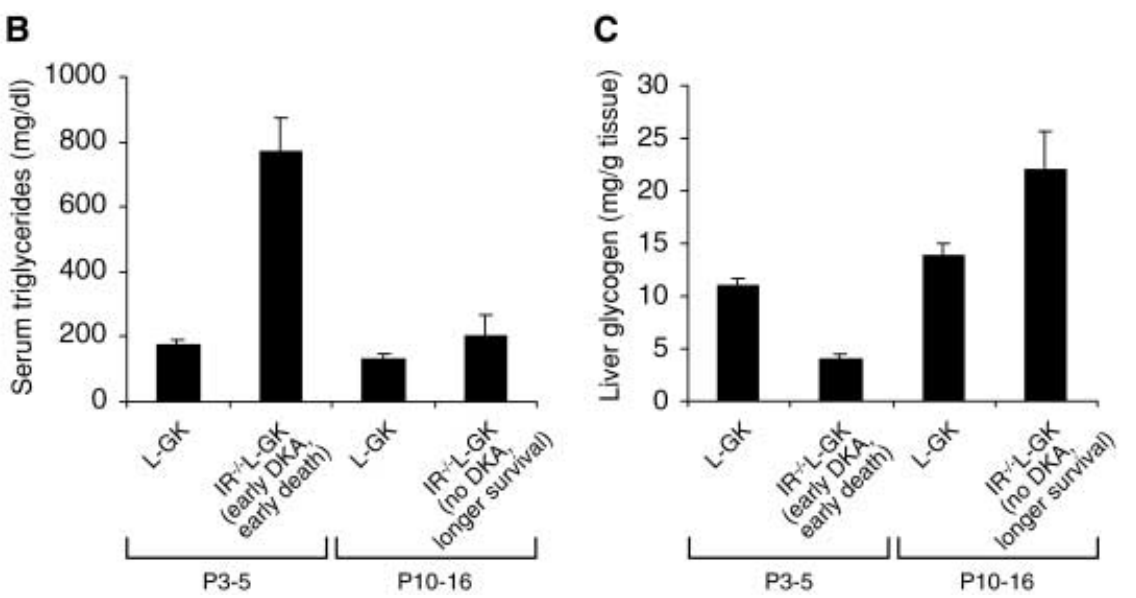

pups which develop DKA and die earlier as well as in their age-matched (postnatal day 3-5 or 10-16) control L-GK siblings. Data shown are means \pm SEM for least five animals in each group 

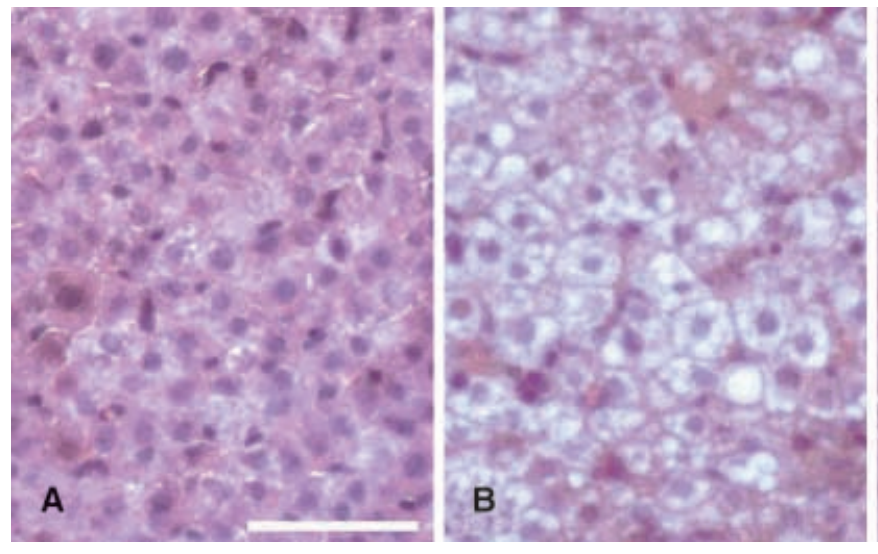

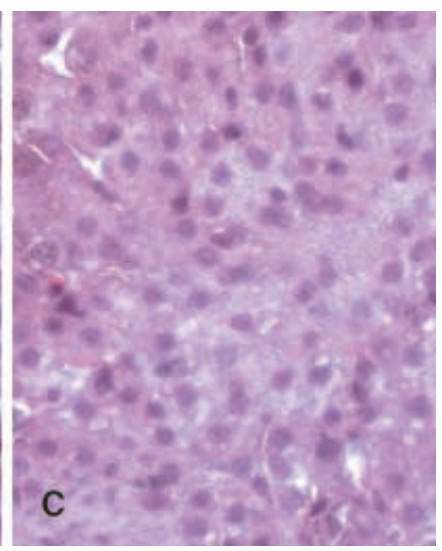

Fig. 5 A-C. Histological analysis of liver of longer-surviving

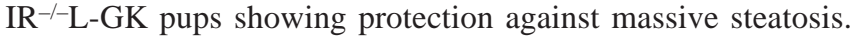
Sections from the liver of a control L-GK mouse at postnatal day 15 (A), a IR-l-L-GK pup with DKA at postnatal day $4(\mathbf{B})$, and a IR ${ }^{-l}$ L-GK pup without DKA at postnatal day 13 (C) were stained with hematoxylin and eosin. $\operatorname{Bar}=40 \mu \mathrm{m}$

to those previously reported for $\mathrm{IR}^{-/-}$mutants. The values found in the longer surviving $\mathrm{IR}^{-/} \mathrm{L}-\mathrm{GK}$ pups with no DKA were lowered but remained higher when compared to those for non-diabetic L-GK control littermates. The glycogen stores in the liver were also depleted in $\mathrm{IR}^{-1} \mathrm{~L}-\mathrm{GK}$ pups developing DKA at an early stage as in $\mathrm{IR}^{-/}$mutants. In contrast, glycogen stores in the longer surviving $\mathrm{IR}^{-1} \mathrm{~L}-\mathrm{GK}$ pups without DKA were comparable, if not higher, than those in their non-diabetic L-GK siblings. As expected, histological analysis of liver sections showed severe steatosis in $\mathrm{IR}^{-/-} \mathrm{L}-\mathrm{GK}$ pups with early development of DKA as in $\mathrm{IR}^{-1-}$ pups. The vacuolated cells with weak staining of the cytoplasm indicate massive fatty acid accumulation (Fig. 5B). The longer-surviving $\mathrm{IR}^{-l}-\mathrm{L}-\mathrm{GK}$ pups without DKA presented only low degrees of fatty acid infiltration (Fig. 5C). DKA and liver steatosis were, however, detected one or two days prior to the death of these longer-surviving IR ${ }^{--}-\mathrm{L}-\mathrm{GK}$ pups.

\section{Discussion}

In this study we have generated a new line of transgenic mice, L-GK, overexpressing the $G K$ gene in the liver under control of the $P A H$ promoter. Consistent with previous transgenic studies using the $P A H$ promoter [18], weak expression of the transgene was also observed in the kidney, while no transgenic expression was found in other classic insulin target tissues such as muscle or adipose tissue. The transgene was also expressed in the livers of newborn transgenic mice. The hepatic GK activity is very low or undetectable in newborn mice or rats [23] but was clearly detectable in transgenic pups. The transgenic mice showed improved glucose tolerance and mild hypoglycaemia under starved conditions as reported for other transgenic mouse lines with hepatic overexpression of GK [11, 12, 14]. The observed increases in serum triglyceride and lactate concentrations in our transgenic line have similarly been reported in other rodents with overexpression of liver GK achieved either by transgenesis or by adenoviral vector-mediated gene transfer $[12,13,15]$.

The $G K$ transgene was subsequently introduced in IR null background by breeding. We have shown in this work that the metabolic disorders developed by $\mathrm{IR}^{-/-}$mutants can be improved and their survival can be prolonged upon restoration of hepatic glucose metabolism by transgenic overexpression of GK selectively in the liver of $\mathrm{IR}^{-/-}$mice. The mixed genetic background of IR $^{-1-}$ L-GK mice (129/Sv, C57BL6, DBA2) could influence this metabolic correction since it was observed only for $16 \%$ of these mice. These results indicate that forced overexpression of hepatic GK can compensate, in part, for the metabolic disturbances seen in $\mathrm{IR}^{-/-}$mutants. The fact that the longer surviving $\mathrm{IR}^{-/} \mathrm{L}-\mathrm{GK}$ pups died before reaching the weaning age suggests that insulin action in other insulin target tissues such as muscle or fat tissue might become more critical by 2 to 3 weeks of age.

The key importance of the liver in glucose homeostasis has emerged from the phenotypes of mice in which tissue-specific IR gene disruption was achieved using the Cre-loxP strategy. Mice lacking IR in the liver (LIRKO) show severe insulin resistance, glucose intolerance and dysregulated hepatic glucose production [5] whereas muscle-specific IR knockout mice displayed normal whole-body glucose homeostasis [4]. Insulin stimulates the transcription of a number of genes involved in glucose metabolism in the liver such as the $G K$ gene [6]. GK is a key regulator in the hepatic control of glucose storage and disposal $[6,24]$. Since $G K$ gene expression was decreased in some diabetic patients $[8,9,10]$, increasing GK activity in the liver appeared as an attractive approach to normalize hyperglycaemia, a common feature of both Type I and Type II diabetes. Hyperglycaemia is the main factor responsible for the development of diabetes-associated retinal, renal, neurological and vascular complications [25]. Overexpression of GK in the liver of transgenic mice 
has been shown to prevent the development of streptozotocin-induced diabetic alterations or high-fat dietinduced hyperglycaemia $[15,16,17]$. Moreover, mice carrying liver-specific $G K$ gene disruption showed decreased hepatic glucose uptake and were moderately hyperglycaemic [26]. The validity of the GK approach was questioned in a subsequent study which showed, using adenoviral vector-mediated $G K$ gene transfer in rats, that the amount of GK overexpression in the liver required to modulate hyperglycaemia in Type II diabetes might have the adverse effect of exacerbating hyperlipidaemia associated with the disease [13].

Using the IR knockout mouse model of extreme insulin resistance, we have shown that transgenic overexpression of GK in the liver of $\mathrm{IR}^{-/-}$mutants can reduce their hyperglycaemia and this was accompanied by restoration of hepatic glycogen stores. At the same time, abnormalities associated with altered lipid metabolism, including hyperlipidaemia, DKA and liver steatosis were improved. However, all animals finally developed DKA and died before the age of 3 weeks, which shows that metabolic disorders resulting from the global lack of insulin signalling cannot be prevented permanently by overexpression of GK in the liver. To further assess the importance of liver GK as a therapeutic target, it could be of interest to transfer the $G K$ transgene in the liver of LIRKO mice to examine whether increased hepatic GK activity can completely compensate or not for the absence of insulin action in the liver in these mice.

Acknowledgements. We thank Dr. S. Woo for providing the human PAH promoter and Dr. P. Iynedjian for the rat GK cDNA. We thank P. Lorès for his valuable help in microinjections and V. Drouet and N. Bazin for their help with animals. M. Jackerott and A. Baudry benefited from Carlsbergfondet (Denmark) and from fellowships from the Fondation pour la Recherche Médicale (France). This work was supported by grants from the Comité de Paris de la Ligue Nationale Contre le Cancer, the Ministère de la Recherche (ACI), Université Paris V and Aventis.

\section{References}

1. Ullrich A, Schlessinger J (1990) Signal transduction by receptors with tyrosine kinase activity. Cell 61: 203-212

2. Accili D, Drago J, Lee EJ et al. (1996) Early neonatal death in mice homozygous for a null allele of the insulin receptor gene. Nat Genet 12: 106-109

3. Joshi RL, Lamothe B, Cordonnier N et al. (1996) Targeted disruption of the insulin receptor gene in the mouse results in neonatal lethality. EMBO J 15: 1542-1547

4. Bruning JC, Michael MD, Winnay JN et al. (1998) A muscle-specific insulin receptor knockout exhibits features of the metabolic syndrome of NIDDM without altering glucose tolerance. Mol Cell 2: 559-569

5. Michael MD, Kulkarni RN, Postic C et al. (2000) Loss of insulin signaling in hepatocytes leads to severe insulin resistance and progressive hepatic dysfunction. Mol. Cell 6: 87-97

6. Pilkis SJ, Granner DK (1992) Molecular physiology of the regulation of hepatic gluconeogenesis and glycolysis. Annu Rev Physiol 54: 885-909

7. Nordlie RC, Foster JD, Lange AJ (1999) Regulation of glucose production by the liver. Annu Rev Nutr 19: 379-406
8. Vionnet N, Stoffel M, Takeda J et al. (1992) Nonsense mutation in the glucokinase gene causes early-onset non-insulin-dependent diabetes mellitus. Nature 356: 721-722

9. Gidh-Jain M, Takeda J, Xu LZ et al. (1993) Glucokinase mutations associated with non-insulin-dependent (type 2) diabetes mellitus have decreased enzymatic activity: implications for structure/function relationships. Proc Natl Acad Sci USA 90: 1932-1936

10. Caro JF, Triester S, Patel VK, Tapscott EB, Frazier NL, Dohm GL (1994) Liver glucokinase: decreased activity in patients with type II diabetes. Horm Metab Res 27: 19-22

11. Niswender KD, Shiota M, Postic C, Cherrington AD, Magnuson MA (1997) Effects of increased glucokinase gene copy number on glucose homeostasis and hepatic glucose metabolism. J Biol Chem 272: 22570-22575

12. Ferre T, Riu E, Bosch F, Valera A (1996) Evidence from transgenic mice that glucokinase is rate limiting for glucose utilization in the liver. FASEB J 10: 1213-1218

13. O’Doherty RM, Lehman DL, Télémaque-Potts S, Newgard CB (1999) Metabolic impact of glucokinase overexpression in liver: lowering of blood glucose in fed rats is accompanied by hyperlipidemia. Diabetes 48: 2022-2027

14. Hariharan N, Farrelly D, Hagan D et al. (1997) Expression of human hepatic glucokinase in transgenic mice liver results in decreased glucose levels and reduced body weight. Diabetes 46: 11-16

15. Ferre T, Pujol A, Riu E, Bosch F, Valera A (1996) Correction of diabetic alterations by glucokinase. Proc Natl Acad Sci USA 93: 7225-7230

16. Shiota M, Postic C, Fujimoto Y et al. (2001) Glucokinase gene locus transgenic mice are resistant to the development of obesity-induced type 2 diabetes. Diabetes 50: 622-629

17. Desai UJ, Slosberg ED, Boettcher BR et al. (2001) Phenotypic correction of diabetic mice by adenovirus-mediated glucokinase expression. Diabetes 50: 2287-2295

18. Wang Y, DeMayo JL, Hahn TM et al. (1992) Tissue- and development-specific expression of the human phenylalanine hydroxylase/chloramphenicol acetyltransferase fusion gene in transgenic mice. J Biol Chem 267: 15105-15110

19. Taylor DS, Dahl HH, Mercer JF, Green AK, Fisher MJ (1989) The effect of streptozotocin-induced diabetes on phenylalanine hydroxylase expression in rat liver. Biochem J 264: 185-190

20. Hogan B, Constantini F, Lacy E (1986) Manipulating the mouse embryo. Cold Spring Harbor Laboratory, Cold Spring Harbor

21. Davidson AL, Arion WJ (1987) Factors underlying significant underestimations of glucokinase activity in crude liver extracts: physiological implications of higher cellular activity. Arch Biochem Biophys 253: 156-167

22. Keppler D, Decker K (1981) Glycogen. In: Bergmeyer HU (ed) Methods of enzymatic analysis, vol 6. Chimie Verlag, Weinheim, pp 11-18

23. Girard J, Perdereau D, Narkewicz M et al. (1991) Hormonal regulation of liver phosphoenolpyruvate carboxykinase and glucokinase gene expression at weaning in the rat. Biochimie 73: 71-76

24. Iynedjian PB, Pilot PR, Nouspikel T et al. (1989) Differential expression and regulation of the glucokinase gene in liver and islets of Langerhans. Proc Natl Acad Sci USA 86: 7838-7842

25. Pickup JC, Williams G (1994) Chronic complications of diabetes. Blackwell Scientific Publishers, Oxford

26. Postic C, Shiota M, Niswender KD et al. (1999) Dual roles for glucokinase in glucose homeostasis as determined by liver and pancreatic $\beta$ cell-specific gene knock-outs using cre recombinase. J Biol Chem 274: 305-315 